\title{
Socioeconomic profile and quality of life In triângulo mineiro and alto Paranaíba region (Brazil)
}

DOI: $10.46932 / \operatorname{sjdv} 2 n 2-014$

Received in: january 1st, 2020

Accepted in: March 30th, 2020

Josimar dos Reis de Souza

$\mathrm{PhD}$ in Geography

Professor at the Federal Center for Technological Education - CEFET-MG

Full Address: CEFET-MG - 25 Olavo Drummond Avenue, Araxá - MG, 38180-510

E-mail: josimarsouza@cefetmg.br

Tatiana Silva Souza

Master in Geography

PhD student at PPGeo at the Federal University of Uberlândia - UFU

Full Address: UFU - 2121 João Naves de Ávila Avenue, Uberlândia - MG, 38408-100

E-mail: tatianasouza@ufu.br

Beatriz Ribeiro Soares

$\mathrm{PhD}$ in Geography

Professor at the Geography Institute of the Federal University of Uberlândia - UFU

Full Address: UFU - 2121 João Naves de Ávila Avenue, Uberlândia - MG, 38408-100

E-mail: brsoares@ufu.br

\begin{abstract}
The present work aims to present the results of the analysis regarding the Socioeconomic Profile of the municipalities that make up the Mesoregion of Triângulo Mineiro/Alto Paranaíba, Minas Gerais, Brazil. The survey and analysis of socioeconomic indicators, from the years 2004 and 2014, aimed to search for devices in order to develop a methodology for analyzing the quality of life of the municipalities that make up the mesoregion, taking into account the specificities of the urban network from the Cerrado Mineiro and the Brazilian urbanization process. It is understood that the quality of life does not depend only on a good offer of essential public services, but on an effective spatial distribution of advanced services regarding health, education, culture, leisure, etc., among the municipalities of the same region. In addition, it is extremely important to consider the population's financial capacity to access these services, a factor that demonstrates the real need to analyze their Socioeconomic Profile. For this analysis, we used the indicators made available by the João Pinheiro Foundation, through the Minas Gerais Social Responsibility Index (IMRS), using the 66 municipalities that make up the mesoregion of Triângulo Mineiro and Alto Paranaíba as the scale of analysis. The data were collected, tabulated and imported into the ArcGIS 10.1 software, in which cartograms were produced. The results presented provided the recognition of the positive evolution overview of the socioeconomic profile, following the Brazilian trend of economic growth experienced in the first decade of the 21 st century. In the analyzed period, there was a significant increase in all the indicators assessed. However, it is worth noting the existence of disparities within the same region, with some municipalities showing a high rate of increase in income and employment, while others have reached medium and low growth peaks. It is worth mentioning that the improvement in quality, especially in terms of income and employment, ended up directly influencing the improvement of the population's quality of life.
\end{abstract}

KEYWORDS: Socioeconomic Profile, Quality of life, Socioeconomic Indicators. 


\section{INTRODUCTION}

The present text intends to present the partial results of doctoral research, whose central objective is the analysis of the levels of life quality in the mesoregion of the Triângulo Mineiro / Alto Paranaíba (TM / AP), based on the analysis of socioeconomic indicators that make up the Minas Gerais Social Responsibility Index (IMRS) made available by the João Pinheiro Foundation. This study seeks to bring contributions to the contemporary perspective related to life quality analysis initiatives, with a focus on seeking improvements in the population's living conditions.

From the analysis of the urbanization process in Brazil and the serious social problems, it is evident the urgent need to seek intervention strategies so that the living conditions of the population improve. Thus, the search for strategies that guarantee the improvement of health conditions, whether physical, mental, intrinsic to the individual, as well as to the environment in which it is inserted, is remarkably important to achieve advances in life quality (SOUZA; SOARES, 2017).

The use of variables and indicators are important in the search for tools that assist public management in decision-making. In this sense, projects have been developed in Brazil and in the world, in which statistical analysis has been used. Studies carried out by WHO, UN, European Union, Brazilian Network of Intelligent and Human Cities, among others, are global examples about seeking a system of indicators that contributed to the improvement of the living conditions in the urban area (LIMA, 2013).

For the analysis addressed here, the results of the IMRS for 2004 and 2014 were used for the municipalities that make up the mesoregion of Triângulo Mineiro / Alto Paranaíba, state of Minas Gerais (Figure 1). 
Figure 1 - Location of the Triangulo Mineiro/Alto Paranaíba Mesoregion. Org.: Souza, 2018.

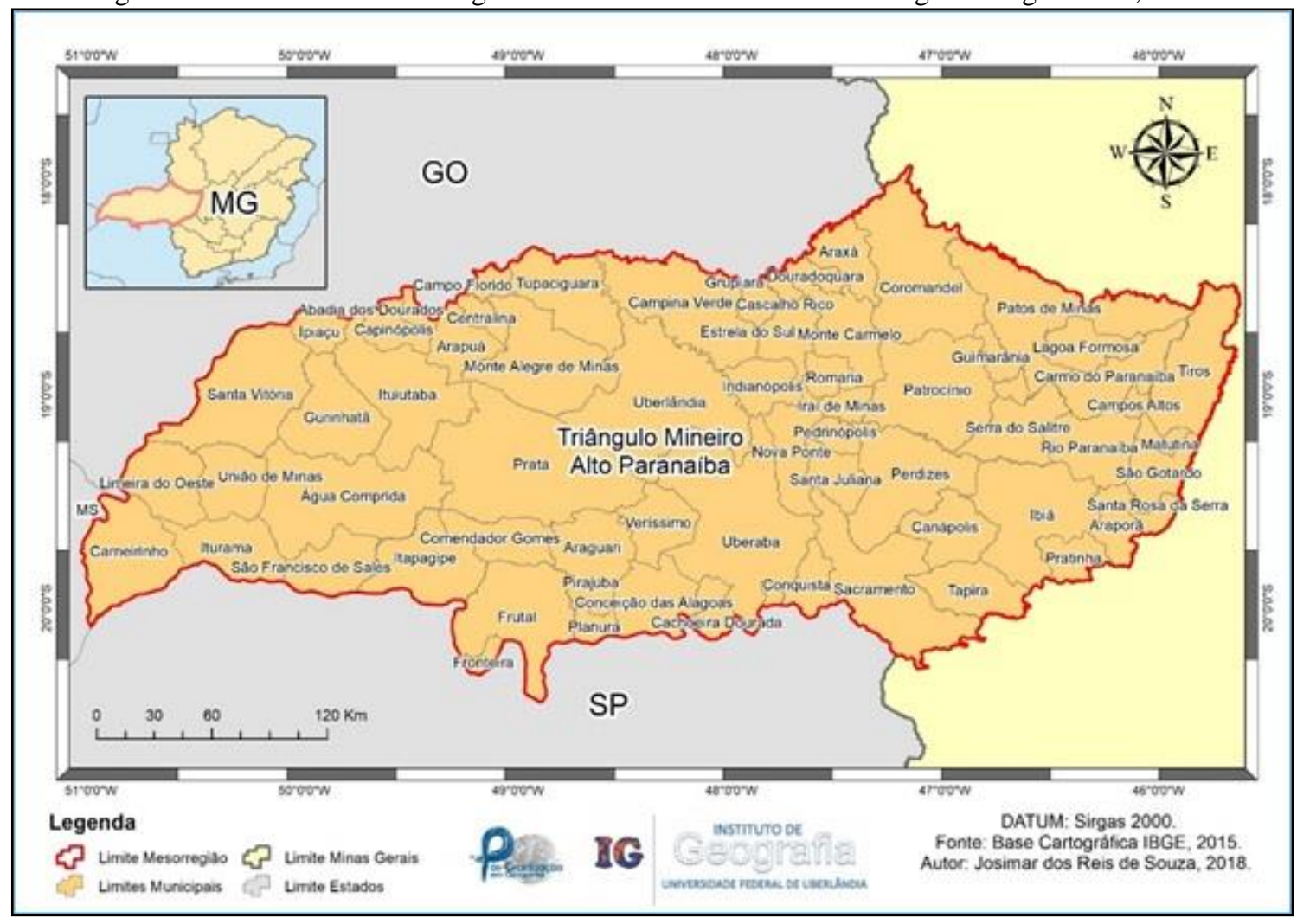

\section{SOCIENOCOMIC PROFILE AND QUALITY OF LIFE IN MESOREGION TM / AP}

Based on the need to create instruments to assist in the management of planning regions, in 2004 the Minas Gerais state government created the Minas Gerais Social Responsibility Index (IMRS), developed by the João Pinheiro Foundation (FJP, 2015). Since then, the index has been applied to all municipalities in Minas Gerais, with results made available annually.

Through IMRS, the municipalities of Minas Gerais have the chance to evaluate the performance of public policies in recent years, in order to correct flaws and / or achieve better results, as well as to use the data provided as a subsidy for public policy planning. It is a large volume of data offered, which can be treated in their real value, or through the indexes made available with the statistical treatment already carried out by the João Pinheiro Foundation (with values ranging between zero and one).

The survey and analysis of socioeconomic indicators, from the years 2004 and 2014, had the intention of seeking devices for the construction of a methodology for analyzing the quality of life of the municipalities that make up the mesoregion, taking into account the specificities of the urban network regarding the Cerrado Mineiro and the Brazilian urbanization process. It is understood that the quality of life does not depend only on a good offer of essential public services, but on an effective spatial distribution of advanced services of health, education, culture, leisure, etc., among the municipalities of the same region. In addition, it is extremely important to consider the population's financial capacity to 
access these services, a factor that demonstrates the real need to analyze their Socioeconomic Profile. For this study, we used the indicators made available by the João Pinheiro Foundation, through the Minas Gerais Social Responsibility Index (IMRS), using the 66 municipalities that make up the mesoregion of Triângulo Mineiro and Alto Paranaíba as the scale of analysis. The data were collected, tabulated and imported into the ArcGIS 10.1 software, in which cartograms were produced.

\subsection{PER CAPITA INCOME AND EMPLOYMENT RATE}

The analysis of the per capita income and employment rate indicator for the years 2004 and 2014 in the study area allows to verify the municipalities that have evolved and declined in these scenarios. This enables to check how much the citizens are inserted in the labor market and how these citizens are regarding the income. These factors are related to quality of life, since the higher the per capita income as well as the number of people working in the formal sector, the higher the households' consumption capacity and financial security are.

Figure 2 shows the per capita income and employment rate of the municipalities of Mesoregion from Triângulo Mineiro and Alto Paranaíba in the years 2004 and 2014.

Regarding per capita income, it is possible to notice that in 2014 most of the municipalities in the mesoregion had an income between 201 and 400 reais, close to the minimum wage of the current year (260 reais). Some municipalities presented values below the minimum wage and only Uberlândia presented values between 401 and 600 reais.

By analyzing the year 2014, it is possible to notice a satisfactory increase in income, with all municipalities showing improvement, mainly as a result of the increase in the minimum wage in recent years, whereas in 2014 it was 724 reais. 
Figure 2 - Analyzed Indicators.

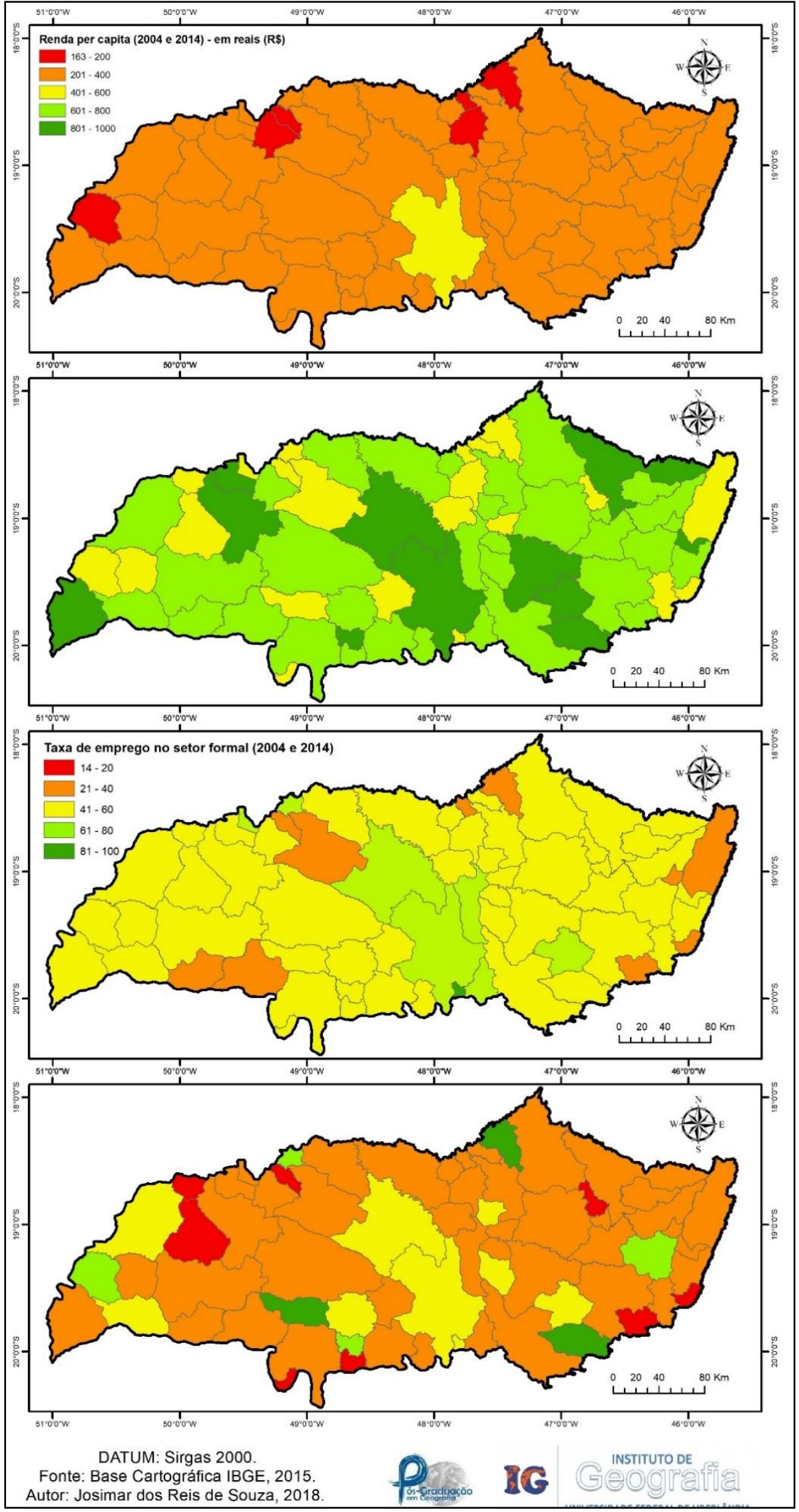

Source: IMRS, 2004 e 2014. Org.: Souza, 2018. 
The result shows that the per capita income of municipalities in the mesoregion has shown significant improvement in recent years, being above the average of several Brazilian municipalities. However, it is worth mentioning that, even with the analysis of the average, it is necessary to consider the specificities, since there are people who receive less than the values presented here.

Regarding the employment rate, in 2004, most municipalities varied between 41 and $60 \%$ of employees in the formal sector. The exceptions were in larger cities (Uberlândia and Uberaba) and also in the cities of Nova Ponte and Araxá, the latter being the reason for employability in the mining sector. These cities had a formal employment rate of 61 to $80 \%$.

In 2014, in general, there was a significant worsening in employment levels in the formal sector. In the largest cities in the region (Uberlândia and Uberaba), there was a downturn in employment levels, mainly caused by the increase in population. Some municipalities showed growth at levels above $80 \%$, a fact related to agribusiness, the sugar and alcohol sector, and in other sectors.

By comparing 2004 with the results of 2014, it is possible to see that the decline in the employment rate in the formal sector followed the Brazilian trend, since in this period, especially close to 2014, the country began to face an economic crisis causing the unemployment rate to increase. People outside the formal sector seek other ways to survive, through informality, which damages their quality of life.

\subsection{FAMILIES WITH PER CAPITA INCOME UP TO 1/2 SALARY AND EXPENSES WITH SOCIAL} ASSISTANCE AND CITIZENSHIP

Figure 3 presents the results concerning the income per capita analysis of $1 / 2$ salary and public expenses with Social Assistance and Citizenship - 2004 and 2014 - of the municipalities in the mesoregion from Triângulo Mineiro / Alto Paranaíba.

In relation to the number of families per thousand inhabitants that in 2004 had a per capita income of up to $1 / 2$ minimum wage, it is possible to highlight that the largest cities in the mesoregion (Uberlândia and Uberaba) were the ones with the lowest levels, a fact related to these cities having the highest GDP in the region and average wages also higher. The other municipalities showed values between 7 and 14 families with this income, showing a relatively low number in relation to national averages. 
Figure 3 - Analyzed Indicators.

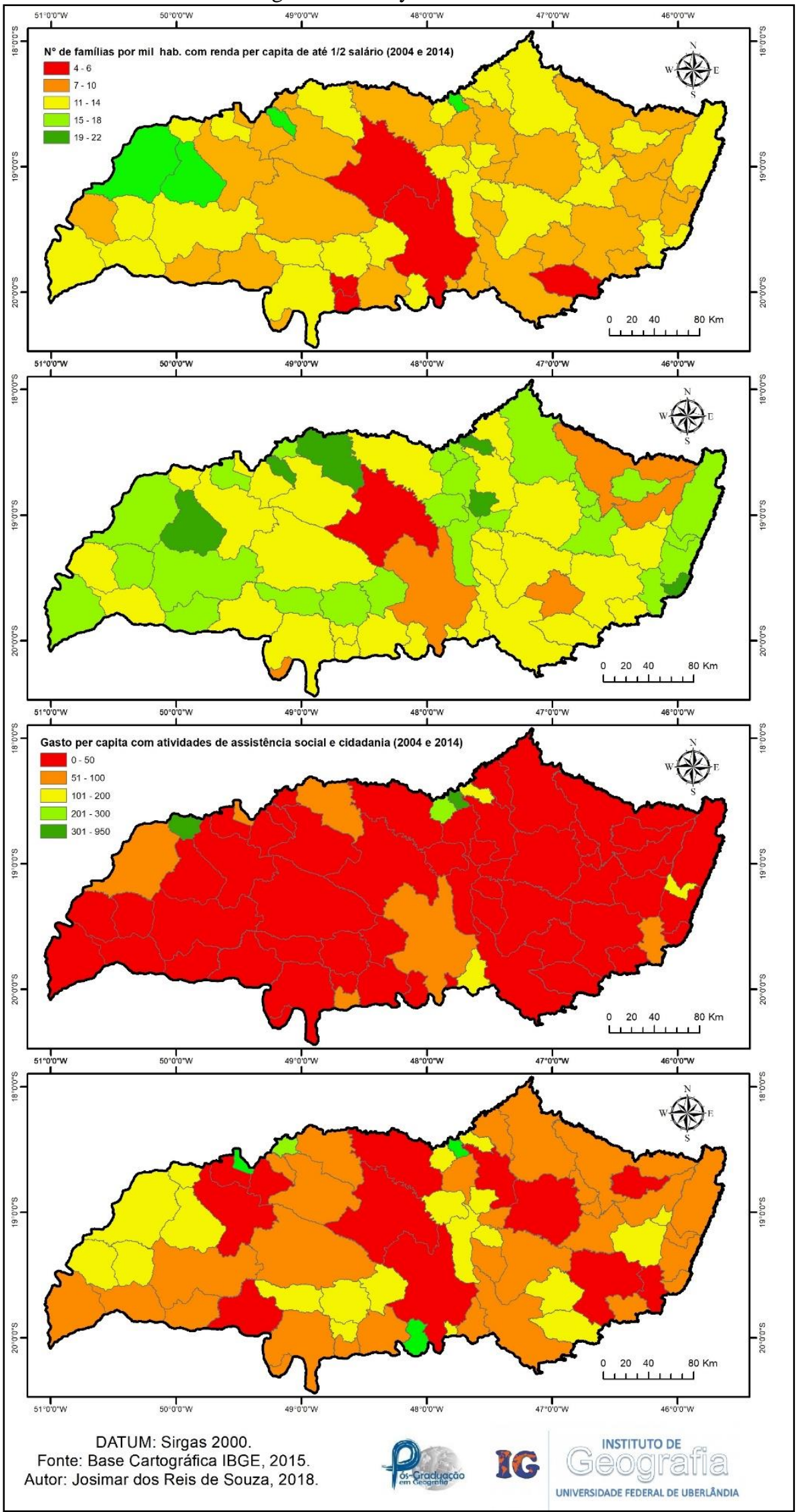

Source: IMRS, 2004 e 2014. Org.: Souza, 2018. 
By evaluating the results of 2014, it is possible to verify the increase in the number of families under these conditions in many of the municipalities in the region studied. This fact points to a decrease in the population's living conditions. Income analysis is essential to seek to understand the living conditions and, consequently, the population's quality of life.

Finally, the last two maps analyze the public effort through expenses on Social Assistance and Citizenship. It is possible to see an increase in spending between 2004 and 2014. In 2004, most municipalities spent up to 50 reais on Social Assistance and Citizenship. In 2014, most of these expenses doubled or tripled. Nevertheless, it is worth considering the inflation of the period, which brings the reflection of the need for greater investments in assistance and citizenship.

\section{FINAL CONSIDERATIONS}

The results presented, from the survey of the IMRS information from the Triângulo Mineiro / Alto Paranaíba mesoregion, demonstrate part of the large collection of information already collected by the João Pinheiro Foundation and made available for free in order to carry out research and, above all, to be used by urban planners. The use of these data is important for the pursuit of improving the population's quality of life.

The problems inherent in contemporary urbanization must be analyzed and solved. For this, the consolidation of databases, such as IMRS, is incredibly important for Minas Gerais as well as for the country. It is through this data that collective intelligence will be built, the quest for solutions will be possible and the improvement in the quality of life will reach acceptable levels in Brazil. Therefore, the search for strategies for the use of indicators, the consolidation of databases and their actual use are necessary to build healthier urban environments. 


\section{BIBLIOGRAPHY}

FUNDAÇÃO JOÃO PINHEIRO (FJP). Índice Mineiro de Responsabilidade Social dos anos de 2002 e 2012. Belo Horizonte: FJP, 2015. Disponível em: http://www.fjp.mg.gov.br. Acesso em: maio de 2018.

INSTITUTO BRASILEIRO DE GEOGRAFIA E ESTATÍSTICA (IBGE). Censo Demográfico de 2010. Rio de Janeiro: IBGE, 2011. Disponível em: http://censo2010.ibge.gov.br/. Acesso em: Maio de 2018.

LIMA, S. C. A construção de Cidades Saudáveis a partir de estratégias de promoção da saúde. LIMA, S. C.; COSTA, E. M. (Orgs.). Construindo Cidades Saudáveis. Uberlândia: Assis Editora, 2013. p. 13-44.

NAHAS, M. I. P. Bases teóricas metodologia de elaboração e aplicabilidade de indicadores intraurbanos na gestão municipal da qualidade de vida urbana em grandes cidades: o caso de Belo Horizonte. 2002. 373 f. Tese (Doutorado em Geografia) - Universidade Federal de São Carlos, São Carlos, 2002.

ORGANIZAÇÃO DAS NAÇÕES UNIDAS (ONU). Estado das Cidades da América Latina e Caribe. Nova Iorque: ONU, 2012. Disponível em: http://es.unhabitat.org/. Acesso em: Maio de 2018.

SANTOS, M. A urbanização brasileira. São Paulo: HUCITEC, 1993. 